\section{Hemoperitoneum after colonoscopy}
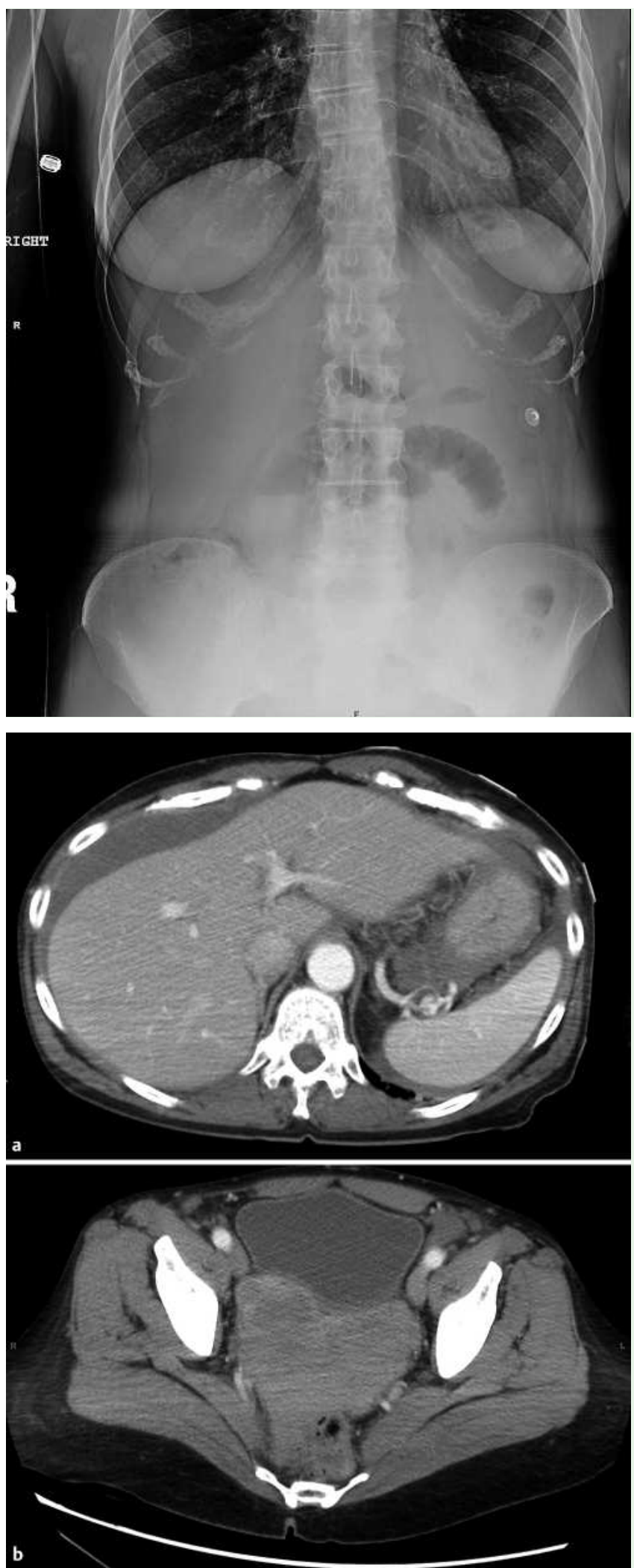

Fig. 1 Abdominal radiograph centered at the diaphragm excludes the presence of pneumoperitoneum.

Fig. 2 Contrast-enhanced axial computed tomography images of (a) abdomen and (b) pelvis show intact spleen and free fluid with density measurements compatible with blood.
Colonoscopy is the primary screening procedure for colorectal cancer and carries very low risk of complications (between $0.3 \%$ and $0.35 \%$ ) [1]. It is estimated that 1.69 million colonoscopies are performed each year in the USA alone [2]. The most common complications are intraluminal gastrointestinal bleeding and colonic perforation [1]. Infrequently, hemoperitoneum occurs, mostly involving damage to the spleen. We present a case of hemoperitoneum following colonoscopy without splenic injury.

A 59-year-old female presented to our emergency department following a syncopal episode 12 hours after an unremarkable screening colonoscopy. Despite minor abdominal discomfort noted after the procedure, she resumed her normal activities. Pertinent history included a prior appendectomy. Besides pallor and minimal abdominal tenderness to palpation, physical exam was within normal limits. Laboratory tests showed a hemoglobin concentration of $10.4 \mathrm{~g} / \mathrm{dL}$ and a hematocrit of $28.8 \%$. Leukocyte count, electrolytes, blood urea nitrogen, and creatinine were normal. Stool was guaiac negative. An abdominal radiograph excluded pneumoperitoneum (๑ Fig. 1). Computed tomography (CT) scans of the abdomen and pelvis showed moderate amounts of free fluid demonstrating a density level suggestive of blood. The spleen appeared normal and there was no free air or extravasation of contrast from the bowel ( Fig. 2a,b). She was monitored for further bleeding and was subsequently discharged after 6 days.

Intra-abdominal hemorrhage, a rare complication of colonoscopy, is most commonly reported in conjunction with splenic injury. Other documented causes of hemoperitoneum after colonoscopies include a torn mesenteric vessel, a ruptured epiploic appendix, and a necrosed intestinal leiomyosarcoma [3-5]. Due to the lack of other findings, it was speculated that the etiology in this case was a torn mesenteric vein. Intra-abdominal adhesions from her appendectomy could have contributed.

Endoscopy_UCTN_Code_CPL_1AJ_2AB 
W. Tagg', S. Woods ${ }^{2}$, R. Razdan ${ }^{3}$, J. Gagliardi ${ }^{3}$, P. Steenbergen ${ }^{3}$

${ }^{1}$ New York Medical College,

Valhalla, New York, USA

2 Department of Gastroenterology, St Vincent's Medical Center, Bridgeport, Connecticut, USA

3 Department of Radiology, St Vincent's Medical Center, Bridgeport, Connecticut, USA

\section{References}

1 Dominitz JA, Eisen GM, Baron TH et al. Complications of colonoscopy. Gastrointest Endosc 2003; 57: 441 - 445

2 Vijan S, Inadomi J, Hayward RA et al. Projections of demand and capacity for colonoscopy related to increasing rates of colorectal cancer screening in the United States. Aliment Pharmacol Ther 2004; 20: 507-515

3 Salvador ME, Lorente PS, Arroyo VM et al. Hemoperitoneum as a complication of diagnostic colonoscopy. Gastroenterol Hepatol 1999; 22: 377

4 Sorrentino M, Terrosu G, Risaliti A et al. Hemoperitoneum caused by lesions to the appendix epiploica. An unusual complication of colonoscopy. Minerva Chir 1996; 51 $835-837$

5 Gonzalez-Rodriguez JF, Tarquis-Alonso $P$ Castano-Pascual $A$ et al. Hemoperitoneum due to necrosis of a small intestinal leiomyosarcoma following colonoscopy. Endoscopy 1993; 25: $253-254$
Bibliography

DOI $10.1055 / \mathrm{s}-2007-995715$

Endoscopy 2008; 40: E136-E137

(c) Georg Thieme Verlag KG Stuttgart · New York . ISSN 0013-726X

Corresponding author

\section{W. Tagg, BA}

New York Medical College

Munger Pavilion, Suite 173

Valhalla

NY 10595

USA

Fax: +1-914-594-4325

willtagg@hotmail.com 